\title{
$34 \mathrm{~m}$ No.c- $71-1$
}

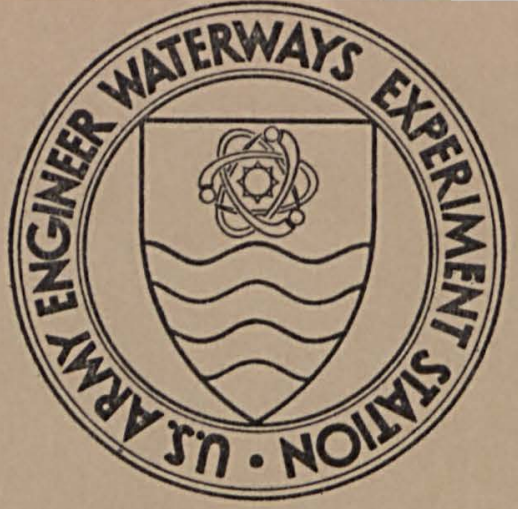

MISCELLANEOUS PAPER C-7I-I

\section{COMPARISON OF IN-SITU AND LABORATORY TEST RESULTS ON GRANITE}

by

R. L. Stowe

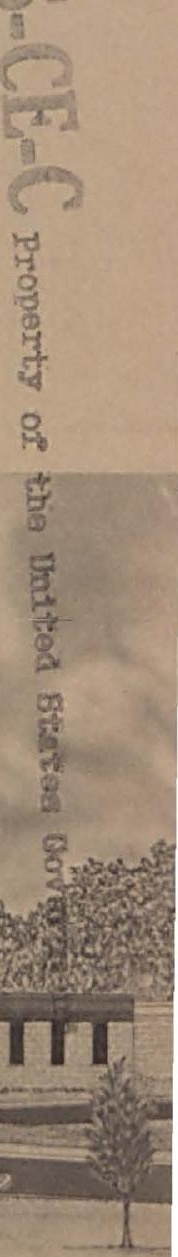

\section{RESEARCH CENTER LIBRARY

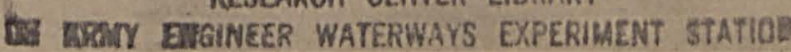 MICKSBURG, MISSISSIPPI \\ January 1971}

Sponsored by U. S. Air Force Systems Command, Space and Missile Systems Organization

Conducted by U. S. Army Engineer Waterways Experiment Station, Vicksburg, Mississippi 


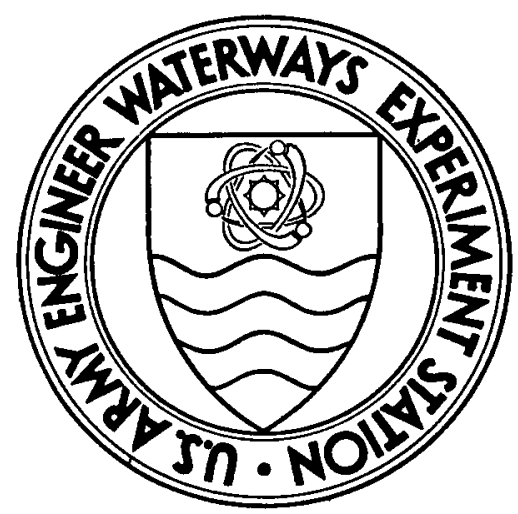

$3 \rightarrow 2$

MISCELLANEOUS PAPER C-7I-I

\section{COMPARISON OF IN-SITU AND LABORATORY TEST RESULTS ON GRANITE \\ by}

R. L. Stowe

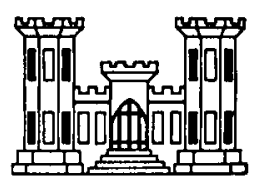

January 1971

Sponsored by U. S. Air Force Systems Command, Space and Missile Systems Organization Conducted by U. S. Army Engineer Waterways Experiment Station, Vicksburg, Mississippi 
FOREWORD

This paper was prepared for presentation at the Fifth Conference on Drilling and Rock Mechanics sponsored by The College of Engineering, The University of Texas at Austin, and The Society of Petroleum Englneers of AIME, 5-6 January 1971 in Austin, Texas. The fleld work was conducted near Cheyenne, Wyoming, and the laboratory work was conducted at the Concrete Division of the U. S. Army Engineer Waterways Experiment Station (WES) under the sponsorship of the Space and Missile Systems Organization (SAMSO), U. S. Air Force Systems Command. The study was coordinated with CPT Rupert G. Tart, Jr., SAMSO Project Officer, and Mr. A. H. Strobeck of TRW Systems Group. The work was conducted during the period from December 1969 through June 1970, and was under the general supervision of Mr. Bryant Mather, Chief of the Concrete Division, and under the direct supervision of Messrs. J. M. Polatty, Chief, Engineering Mechanics Branch, W. O. Tynes, Chief, Concrete and Rock Properties Section, and R. L. Stowe, Project officer. Mr. D. L. Ainsworth assisted with the field work. Mr. Stowe prepared this paper. The paper was approved for presentation and publication by the sponsor and by the Office, Chief of Engineers. Directors of the WES during the investigation and the preparation and publication of the paper were COL Levi A. Brown, CE, and COL Ernest D. Peixotto, CE. Technical Director was Mr. F. R. Brown. 


\section{ABSTRACT}

Four NX-diameter holes were diamond-drilled in competent granite. Samples of the recovered core were used in laboratory tests. A borehole, plate-bearing device known as a Goodman jack was used to perform loaddeformation tests on the rock in the core hole. The samples used in the laboratory tests were taken from depths in the hole at or within $5 \mathrm{ft}$ of those at which the jacking tests were made. Borehole camera records, compressional and shear wave velocities, and densities were measured. Dynamic elastic constants were computed for the in-situ material, while comparative data (except camera records) were obtained in the laboratory. These data were examined to evaluate the significance of the in-situ modulus of deformation $\left(\bar{E}_{d}\right)$, the value computed from Goodman-jack tests: Average test results show an excellent correlation between in-situ and laboratory data. The ratio of laboratory to field deformatinn madulug ranges from 9.82 to 7.21 for 3000 - and 9000 -psi stress levels, respectively. The dynamic modulus ratio, $\frac{E_{D} \text { field }}{E_{D} \text { lab }}$, is 1.02 ; the compressional wave velocity ratio, $\frac{v_{p} \text { field }}{\nabla_{p} \text { lab }}$, is 0.94 ; the shear wave velocity ratio, $\frac{\nabla_{s} \text { field }}{\nabla_{s} \text { lab }}$, is 1.12 ; and the density ratio, $\frac{\gamma_{\text {field }}}{\gamma_{\text {lab }}}$, is 0.95. 


\section{COMPARISON OF IN-SI'TU AND LABORATORY}

TEST RESUJ,TS ON GRANITE

INTRODUCTION

This paper presents and discusses some of the test results obtained from a large rock mechanics program. That portion of the program discussed in this paper was conducted for purposes of developing data for use in a computer code used in connection with the design of a medium-size structure. As an outgrowth of the analysis of these data, several questions arose. One concerned the accuracy of the in-situ deformation modulus $\left(E_{d}\right)$; 1.e., was the $E_{d}$ calculated from pressure-displacement data, the value computed from NX plate-bearing tests, realistic? The plate-bearing device used in this program was the Goodman jack. ${ }^{1}$

Several approaches could have been used in getting a reasonable answer to the above question. One approach would be to evaluate other similar devices in the same rock mass in which the Goodman jack was used; however, the expense would be prohibltive. Other deformation moduli tests, such as flat-jack and radial jacking tests and large plate-bearing tests, are described in reference 2. Another approach would be to rely on published data which would give an approximate figure. $\mathrm{Coon}^{3}$ states that in-situ tests indicate that the $E_{d}$ is generally from one-half to one-tenth of the laboratory modulus of elasticity. This range is given 
for a large number of other types of plate-jacking tests; however, one could assume it applies to borehole deformation tests also. An examination of comparative values suggests that the in-situ $E_{d}$ obtained for the rock mass in question was reasonable.

\section{FIELD STUDY}

The geologic characteristics of a competent granite mass were we 11 documented in the preliminary phases of the project. Of the numerous NX-diameter holes diamond-drilled into the granite, only the data recorded in four of the holes are used in this paper. The boreholes were drilled vertically to a depth of $150 \mathrm{ft}$ and were water-filled at the time all down-hole tests were run.

The following in-situ tests were conducted:
a. Borehole photography.
b. Compressional and shear wave velocities.
c. Gamma density.
d. NX plate bearing.

Borehole photography was accomplished using the Waterways Experiment Station (WES) NX-size camera with color film. The paper by Burwell and Nesbitt ${ }^{4}$ gives details of the camera. Compressional and shear wave velocities, $v_{p}$ field and $v_{s}$ fleld, respectively, as well as densities, $\checkmark$ field, were obtalned using the Birdwell three-dimensional velocity and gamma density logging equipment. 5 The $\nabla_{p}$ and $\nabla_{s}$ were measured using compressional crystals. Both of the Birdwell tools as well as the camera 
are used in continuous logging operations. The dynamic modulus of elasticity, $E_{D}$ field, was computed for the in-situ material from velocity values. Deformation moduli $\left(E_{d}\right)$ were calculated from data recorded with the plate-bearing device. The jack was obtained on loan to WES from the Slope Indicator Company of Seattle, Washington. The Goodman jack, plate 1, supplies a unidirectional self-equflibrating pair of forces to opposite sectors of a borehole by means of racetrack pistons and a movable plate. Two LVDT transducers are mounted within the jack and monitor the displacement of the movable bearing plate. The bearing plates are forced apart by hydraulic pressure; maximum jack pressure is $10,000 \mathrm{psi}$, and maximum pressure applied to rock is 9300 psi. With the hydraulic pressure applied to the jack $\left(Q_{h}\right)$, the measured displacement $\left(U_{d}\right)$, Poisson's ratio $(v)$, and a constant value ( $K$ ) known, the modulus of deformation may be obtained from the following equation:

$$
E_{d}=2.40 \mathrm{~K}(\mathrm{v}) \frac{Q_{h}}{U_{d}}
$$

The constant, $\mathrm{K}$, is derived from theoretical considerations given in the appendix to the paper by Goodman et $\mathrm{al}^{1}$ and corresponds to the average displacement under the loaded area of the jack.

Values of $v_{p}, v_{s}$, and $\gamma$ were recorded continuously for the full depth of the borehole. Color pictures were also obtained for the full depth of the boreholes. The plate-bearing tests were run at 18 different locations in the four holes. These locations were selected so as to Include competent rock, rock with joints having angles less than 45 degrees 
and more than 45 degrees to the axis of the hole, and broken rock. Table 1 gives the hole number, the depth where the plate-bearing tests were run, and the basis for selecting the test depths. The selection of plate-bearing test locations was made with the aid of core logs, Birdwe 11 logs, and camera records.

\section{LABORATORY STUDY}

NX-size rock cores were tested in the laboratory. The majority of samples were taken from depths in the boreholes at or within $5 \mathrm{ft}$ of those at which the plate-bearing tests were made.

The laboratory tests included:
a. Compressive strength $\left(\mathrm{C}_{\mathrm{o}}\right)$.
b. Young's modulus of elasticity.
c. Compressional and shear wave velocities.
d. Density.

The $\mathrm{C}_{0}$ tests were run in accordance with a method of test for unconfined compressive strength of rock core specimens being considered by ASTM Committee D-18. When two specimens were avallable from one length of core, one was tested dry and the other after Immersion in water for $48 \mathrm{hr}$ prior to testing; all other cores were tested dry. Secant moduli of elasticity ( $E$ ) were computed from the stress-strain data at stress levels of 3000 and 9000 psi. Another method being considered by ASTM Committee D-18 for deformation modull of intact core specimens of rock In compression was followed. 
The $v_{p}$ and $V_{s}$ were calculated from pulse travel times obtained using compression and shear crystals. The method being considered by ASIM Comnittee D-18 for laboratory determination of ultrasonic pulse velocities and elastic constants of rock was followed with the exception of a modification to the transmitter and receiver housings. In order to measure accurately the pulse travel time it was necessary to apply a slight pressure to the crystals. By applylng this pressure, it was possible to introduce more shear energy into the specimen. The density values were obtained by the water-displacement technique.

\section{DISCUSSION OF RESULTS}

Typical hydraulic pressure versus diametrical displacement curves are glven in plate 2. Ustig equation 1, three secant moduli of deformation were calculated for each curve where both loading and unloading data were available. The first modulus represents the maximum load and total displacement, or that portion of the curve which is concave upwards (changling pressure-displacement slope) and that portion which is linear (constant pressure-displacement slope). The 1 inear portion of the curves represents an elastic response when all stress-relieved cracks and/or joints are closed. The second modulus was taken at $3000 \mathrm{ps} 1$ and represents the concave upwards portion for approximately 80 percent of the pressuredisplacement curves. The third modulus represents the entire unloading pressure curve and represents any residual displacement. The three moduli are represented by the dashed 1 ines in $\mathrm{fig}$. (a) on plate 2 . 
All loading-unloading curves exhibit some residual displacement. At those test depths where competent rock was encountered, the residual displacement is caused by asperities being crushed on the borehole wall and closure of stress-relieved cracks due to drilling. Where jointed rock was tested, the residual displacement is caused by crushed asperfties plus stress-relieved cracks and permanent set due to joint closure or slippage. The average permanent displacement for the competent rock and the rock with high-angle joints is $0.0064 \mathrm{in.}$ (see fig. (b) and (c), plate 2) and for the low-angle jointed rock, $0.0119 \mathrm{in.}$ (see fig. (a), plate 2). The low-angle jointed rock $(<45 \mathrm{deg}$, but generally $0-20 \mathrm{deg})$, where the joints are either opened or filled, has a permanent displacement twice that of the competent rock. The spacing and the frequency of high-angle jointing were observed to be less than were the spacing and frequency of the lowangle jointing; this also would contribute to residual displacements. For higher pressure levels (greater than 9000 psi) and greater rates of loading (greater than 15 psi per sec, which was the loading rate used during this study), permanent displacements in the jointed rock could be quite different from that observed in this investigation.

The Goodman jack appears to be fairly sensitive to differences in physical condition of the in-situ rock as these were encountered in the rock tested during this investigation. All three in-situ modulf of deformation correlate quite well with the joints recorded with the borehole camera and noted on the core logs. Plates 3-4 show that the joint frequency as well as the physical condition of the joints (open 
or filled, low- or high-angle) influence the in-situ modulus value. For plates 3,4 , and 5 , joint frequency is joints per foot, or all joints $1 / 2 \mathrm{ft}$ above and below the center of the bearing plates of the jack. The modulus is one-half the maximum in those zones where open or filled low-angle joints occur; this is true for all secant moduli. The modulus value increases where high-angle joints occur, and the highest modulus values occur in zones of competent rock with the exception of two unloading secant modul1. The moduli for zones where tigkt high-angle joints occur are similar to the moduli for competent zones. The average moduli for the low- and high-angle and competent rock zones are given below.

\begin{tabular}{lccc} 
Tabulation of Average $E_{d}{ }^{\prime} s, \times 10^{6}$ & psi \\
\hline & $\underline{3000}$ & $\underline{2000}$ & Unloading \\
Low-angle zones & 0.70 & 0.90 & 1.54 \\
High-angle zones & 1.05 & 1.56 & 3.01 \\
Competent zones & 1.08 & 1.62 & 2.70
\end{tabular}

The average rompressive strength was found to he 21 , n6n nei and 18,550 psi for specimens tested dry and wet, respectively. Plate 6 is a typical stress-strain plot of the intact rock core. The average values for static Young's modulus of elasticity for the 3000-ps 1 and 9000-psi stress levels are $7.61 \times 10^{6}$ psi and $8.59 \times 10^{6}$ psi, respectively, while the average Poisson's ratio was found to be 0.26 .

The overall in-situ deformation moduli at the 3000- and 9000-psi stress level, as well as for the unloading portion of the curve, are given below. 
Tabulation of Average In-Situ $\mathrm{E}_{\mathrm{d}}$ 's $\times 10^{6} \mathrm{psi}$

$\frac{\text { Stress Leve1, psi }}{\frac{9000}{3000}} \frac{\text { Unloading }}{1.19}$

These moduli correlate quite closely with values reported by Kruse ${ }^{2}$ for plate-bearing tests at the Oroville Dam site. The average modulus reported by Kruse was $1.5 \times 10^{6}$ psi with flat-jack and tunnel tests being somewhat higher. The ratio of laboratory to field deformation modulus ranges from 9.82 to 7.21 for 3000 - and $9000-p s i$ stress levels, respectively. A similarly determined ratio for the unloading modulus is 4.01 .

The in-situ unloading $E_{d}$ reported above is in the mid-range given by Coon; ${ }^{3}$ i.e., from one-half to one-tenth of the intact $E$; ours is one-fourth.

The low in-situ deformation modull are primarily the result of the discontinulties within the rock mass.

When the $v_{p}, v_{s}, \gamma$, and $E_{D}$ results of intact cores are used with simflar in-situ results, an assessment of the in-situ rock quality is obtained. In-situ discontinulties can be assessed by calculating the velocity and the dynamic modulus ratio. This type of Indexing has been reported by others: ${ }^{2,3}, 6$ for example, plates 7 and 8 graphically show how the velocity index $\frac{V_{p} \text { field }}{V_{p} l a b}$ can be used to assess rock mass quality. The velocity index is normally greater than 0.80 in zones where there are less than 10 discontinuities per $10 \mathrm{ft}$, and drops to 0.50 for highly jointed zones. The compressional wave 


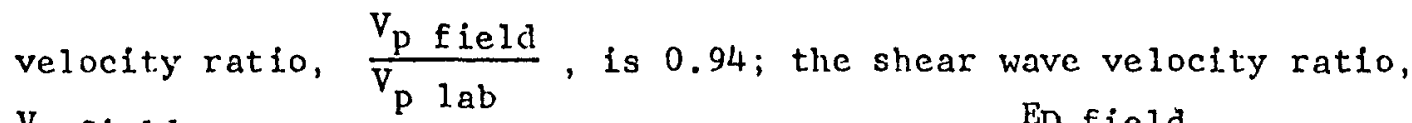
$\frac{V_{s} \text { field }}{V_{s} \text { lab }}$, is 1.12 ; the dynamic modulus rat1o, $\frac{E_{D} \text { field }}{E_{D} \text { lab }}$, is 1.02 ; and the density ratio, $\frac{\gamma_{\text {field }}}{\gamma_{\text {lab }}}$, 1s 0.95 . Table 2 presents both the field and laboratory physical property data.

At this point, a question may be raised as to why the velocity, dynamic modulus, and density ratios herein reported are very close to unity, while the deformation modulus ratio is four to eight times unity.

When a jointed rock mass is subjected to a load above that which it is supporting, a joint block can be displaced some distance from its original position. Given load sufficient to cause closure of a joint or slippage along a joint, energy is expended; hence, a permanent set and a low deformation modulus results as seen in fig. (a), plate 2. In competent rock, energy is lost to the closure of microfractures and the crushing of asperities as seen in fig. (c), plate 2 . When intact rock cores are loaded in compression, they have the advantage over jointed rock in that energy is only lost to the closure of a few microfractures; i.e., before ylelding occurs. Hence, a high deformation modulus is generally measured. Other factors, such as size effects, test configuration, test methods, etc., certalnly have some effect on the modulus value.

In a competent rock mass, one in which the joints are tight while the joint spacing is large and the $c_{0}$ is high, the nondestructive test results should be cunsistent as well as equal to results from intact specimens. If the parameter determined is an inherent characteristic 
of the materfal, it should be the same whether measured in the fleld or in the laboratory. When a slight difference does occur, it is logically attributed to experimental error. When large differences are noted, there is normally good reason. An example is seen in plate 8 where the velocity ratio drops to 0.5 due to the high fracture frequency between depths 35 and $45 \mathrm{ft}$.

\section{SUMMARY}

The velocity, dynamic modulus, and density ratios are indicative of a stable and competent rock mass. Based on this fact and using engineering judgment, the in-situ deformation moduli were deemed realistic for both the computer input and the design of the proposed structure.

The velocity index is a reasonable tool for ascertaining in-situ rock quality. The effect of discontinuities in a rock mass are quickly assessed using the velocity index with fracture frequency.

The $V_{p}$ and $E_{D}$ data obtained with Birdwell's logs appear less sensitive to discontinuities than do the data obtained with the platebearing device known as the Goodman jack.

The data obtained from the Goodman jack should be correlated with visual evidence such as obtained from examination of cores or borehole canera records.

The in-situ deformation modulus decreases with an increase in joint frequency for both the low- and high-angle joint zones. 


\section{ACKNOWLEDGIMENTS}

The author is particularly grateful to Mr. D. L. Ainsworth for his perseverance during the field phase of this investigation and to Mr. Bryant Mather for his helpful criticism and review of this manuscript.

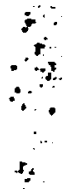




\section{REFERFNCES}

1. Goodman, R. E., Van, T. K., and Heuze, F. E., "The Measurement of Rock Deformability in Boreholes," Tenth Symposium on Rock Mechanics, University of Texas, Austin, Texas, May 1968.

2. Determination of the In-Situ Modulus of Deformation of Rock, ASTM Special Technical Publication 477, Philadelphia, Pa., June 1970.

3. Coon, Richard F., Correlation of Engineering Behavior with the Classification of In-Situ Rock, University of Illinols, Ph.D. Thesis, 1968.

4. Burwell, E. B., and Nesbitt, R. H., "The NX Borehole Camera," Mining Engineering, August 1954.

5. Christensen, D. M., "A Theoretical Analys is of Wave Propagation in Fluid-Filled Drill Holes for the Interpretation of the 3-Dimensional Velocity Log," Transactions, Fifth Annual Logging Symposium, Midland, Texas, 3-15 May 1964 .

6. Stagg, K. G., and Zienkiewicz, O. C., Rock Mechanics in Engineering Practice, John Wiley \& Sons, New York, 1968. 


\begin{tabular}{|c|c|c|}
\hline $\begin{array}{l}\text { Hole } \\
\text { No. }\end{array}$ & $\begin{array}{l}\text { Test } \\
\text { Depth, ft }\end{array}$ & Basis for Selecting Depths \\
\hline 1 & $42.9-A$ & High-angle joint zone, joints filled* \\
\hline 1 & $42.9-B$ & $\begin{array}{l}\text { Anisotropy effects, orientated } 90 \text { deg from } \\
\text { 42.9-A test depth }\end{array}$ \\
\hline 1 & 44.0 & $\begin{array}{l}\text { Low-angle joint zone, joints healed with tan } \\
\text { stained material** }\end{array}$ \\
\hline 1 & 82.25 & $\begin{array}{l}\text { Competent rock; depth. is } 3 \mathrm{ft} \text { above apparent } \\
\text { cavity as shown on field caliper log. }\end{array}$ \\
\hline 1 & 83.5 & $\begin{array}{l}\text { High-angle joint zone, joints open; depth is } \\
\text { l.5 ft above apparent cavity; core log shows } \\
\text { broken rock } \leq 0.3 \mathrm{ft} .\end{array}$ \\
\hline 1 & 84.45 & Same as above but near edge of apparent cavity. \\
\hline 1 & 85.25 & Same as at 83.5 but on edge of apparent cavity \\
\hline 1 & 89.25 & $\begin{array}{l}\text { Same as at } 83.5 \text { but on bottom edge of apparent } \\
\text { cavity }\end{array}$ \\
\hline 2 & 22.0 & Competent rock \\
\hline 2 & 29.5 & Competent rock \\
\hline 2 & 30.5 & $\begin{array}{l}\text { Aplite dike and low-angle joint zone; jolnts } \\
\text { stained }\end{array}$ \\
\hline 2 & 57.8 & Competent rock \\
\hline 3 & 18.0 & High- and low-angle joints; joints stained \\
\hline 3 & 23.0 & $\begin{array}{l}\text { Aplite dike and low-angle jolnt zone; jolnts } \\
\text { clean }\end{array}$ \\
\hline 3 & 32.5 & Low-angle joint zone; joints healed \\
\hline 3 & 41.0 & $\begin{array}{l}\text { Low-angle joint zone; joints stained } \\
\text { (Continued) }\end{array}$ \\
\hline
\end{tabular}

* Filled - green-gray material or clay.

** Healed - a discontinuity exists but has been healed with some type of solution. 
Table I (Concluded)

\begin{tabular}{|c|c|c|}
\hline $\begin{array}{l}\text { Hole } \\
\text { No. }\end{array}$ & $\begin{array}{l}\text { Test } \\
\text { Depth, ft }\end{array}$ & Bas is for Selecting Depths \\
\hline 3 & 50.0 & Competent rock \\
\hline 3 & 52.0 & Competent rock \\
\hline 4 & 50.5 & $\begin{array}{l}\text { Competent rock; test depth may correlate with } \\
\text { same test depth in } \mathrm{P} 6-2 \mathrm{~A}-5\end{array}$ \\
\hline 4 & 79.0 & Competent rock \\
\hline
\end{tabular}


Table 2

Pingsical Property Data

\begin{tabular}{|c|c|c|c|c|c|c|c|c|}
\hline \multirow[b]{2}{*}{$\begin{array}{l}\text { Hole } \\
\text { No. }\end{array}$} & \multirow[b]{2}{*}{ Depth, ft } & \multicolumn{7}{|c|}{ Laboratory Data } \\
\hline & & $\begin{array}{r}\text { Comp } \\
\text { Strg } \\
\text { psi } \\
\end{array}$ & $\begin{array}{c}\text { Eat } \\
3000 \mathrm{psi} \\
\times 10^{6} \mathrm{psi} \\
\end{array}$ & $\begin{array}{r}\text { E at } \\
9000 \mathrm{psi} \\
\times 10^{6} \mathrm{ps} 1 \\
\end{array}$ & $\begin{array}{r}\mathrm{E}_{\mathrm{D}} \\
\times 10^{6} \mathrm{ps} 1 \\
\end{array}$ & $\begin{array}{r}\nabla_{p} \\
\underline{p p 8} \\
\end{array}$ & $\begin{array}{r}V_{s} \\
\text { Eps } \\
\end{array}$ & $\begin{array}{l}\text { Density } \\
1 \mathrm{~b} / \mathrm{cu} \mathrm{ft}\end{array}$ \\
\hline \multirow[t]{9}{*}{1} & $12.4-13.9$ & 21,320 & 5.45 & 6.67 & $\because .33$ & 16,806 & 8,890 & 164.5 \\
\hline & $21.6-23.3$ & 20,300 & 7.50 & 8.18 & 7.83 & 17,227 & 9,102 & 167.5 \\
\hline & $22.3-23.6$ & 20,120 & 7.50 & 8.57 & $\because .86$ & 17,390 & 9,094 & 167.9 \\
\hline & $41.0-43.3$ & 20,400 & 8.57 & 9.23 & 8.87 & 19,027 & 9,591 & 167.9 \\
\hline & $44.8-46.6$ & $19,260 *$ & $\ldots$ & - & 5.46 & 18,772 & 10,026 & 167.5 \\
\hline & $44.8-46.6$ & 19,280 & - & - & $\$ .49$ & 19,699 & 9,932 & $167 . .5$ \\
\hline & $44.8-46.6$ & 22,480 & 9.23 & 9.52 & 9.46 & 18,772 & 10,026 & 167.5 \\
\hline & $57.0-58.1$ & 20,630 & 7.50 & 8.57 & 8.42 & 19,153 & 9,276 & 168.2 \\
\hline & $141.3-142.5$ & 20,140 & 8.57 & 9.00 & 9.48 & 19,662 & 9,913 & 168.0 \\
\hline \multirow[t]{7}{*}{2} & $17.9-19.4$ & 21,070 & 6.32 & 8.57 & 8.03 & 17.039 & 9,278 & 167.5 \\
\hline & $24.5-26.6$ & 18,070 & 6.67 & 8.18 & 8.13 & 17,126 & 99,072 & 175.4 \\
\hline & $28.0-29.1$ & $18,210 *$ & - & - & 8.58 & 16,485 & 9,791 & 168.9 \\
\hline & $31.0-31.6$ & - & - & - & 5.40 & 17,570 & 7,367 & 165.3 \\
\hline & $54.2-56.2$ & 22,260 & 6.67 & 7.89 & 7.27 & 16,877 & 8,751 & 167.0 \\
\hline & $65.8-68.5$ & 22,290 & 7.32 & 8.57 & 7.75 & 16,889 & 9,048 & 168.7 \\
\hline & $78.5-80.8$ & 19,920 & 7.50 & 7.50 & 8.22 & 17,717 & 9,179 & 171.7 \\
\hline \multirow[t]{8}{*}{3} & $19.8-20.6$ & 20,840 & 6.00 & 7.50 & 7.70 & 15,424 & 9,410 & 167.2 \\
\hline & $36.4-38.2$ & 20,340 & 7.50 & 8.78 & 7.76 & 17,445 & 9,063 & 166.4 \\
\hline & $36.4-38.2$ & $17,800 *$ & - & - & $\varepsilon .21$ & 19,225 & 9,190 & 166.4 \\
\hline & $39.0-40.7$ & 21,980 & 8.57 & 9.00 & 8.60 & 18,412 & 9,532 & 166.4 \\
\hline & $41.7-43.0$ & $18,400 *$ & -- & -- & 8.20 & 18,592 & 9,247 & 166.4 \\
\hline & $41.7-43.0$ & $19,100 *$ & -- & -- & 8.30 & 19,122 & 9,261 & 166.4 \\
\hline & $57.4-58.9$ & 22,176 & 6.67 & 8.18 & -- & -- & -- & - \\
\hline & $139.4-142.6$ & 24,460 & 8.57 & 9.47 & 8.61 & 17,625 & 9,605 & 167.7 \\
\hline \multirow[t]{2}{*}{4} & $66.2-67.7$ & 22,730 & 7.50 & 9.00 & 8.24 & 18,592 & 9,247 & 167.0 \\
\hline & $92.1-93.1$ & 20,250 & 10.00 & 11.25 & 5.87 & 19,302 & 10,232 & 167.4 \\
\hline
\end{tabular}

Wetted specimen.

NOTES: $E=$ secant modulus of elasticity

$E_{D}=$ dynamic modulus of elasticity 
Table 2 (Concluded)

Field Data

\begin{tabular}{|c|c|c|c|c|c|c|c|c|}
\hline \multirow[b]{2}{*}{$\begin{array}{r}\text { Hole } \\
\text { No. }\end{array}$} & \multirow[b]{2}{*}{$\begin{array}{c}\text { Depth } \\
\mathrm{ft} \\
\end{array}$} & \multicolumn{3}{|c|}{ Goodman ack } & \multicolumn{4}{|c|}{ Birdwe 1 1} \\
\hline & & $\begin{array}{l}3000 \mathrm{ps} 1 \\
\times \quad 10^{6} \mathrm{ps} 1 \\
\end{array}$ & $\begin{array}{l}9000 \text { ps } 1 \\
\times \quad 10^{6} \mathrm{E}: \mathrm{si} \\
\end{array}$ & $\begin{array}{l}\text { Unloading } \\
\times 10^{6} \mathrm{psi} \\
\end{array}$ & $\begin{array}{r}E_{D} E_{D s i} \\
\times 10^{6} \text { psi } \\
\end{array}$ & $\begin{array}{c}v_{p} \\
\mathrm{ft} / \mathrm{sec}^{-}\end{array}$ & $\begin{array}{c}V_{s} \\
f t / s e c\end{array}$ & $\begin{array}{l}\text { Density } \\
1 \mathrm{~b} / \mathrm{cu} \mathrm{ft}\end{array}$ \\
\hline \multirow{4}{*}{1} & 42.90 & 1.22 & 1.91 & 3.21 & 9.08 & 16,732 & 10,619 & 160.5 \\
\hline & 44.00 & -- & -- & -- & 8.86 & 16,462 & 10,534 & 160.5 \\
\hline & 44.00 & 0.918 & 0.857 & 1.48 & 8.86 & 16,462 & 10,534 & 160.5 \\
\hline & 89.25 & 0.826 & 1.30 & 2.50 & 8.18 & 16,462 & 10,047 & 156.1 \\
\hline \multirow[t]{5}{*}{2} & 29.5 & 0.587 & 1.08 & 1.44 & 8.44 & 16,705 & 10,155 & 156.1 \\
\hline & 30.5 & 0.692 & $0.66 \AA$ & - & 7.81 & 15,856 & 9,887 & 156.1 \\
\hline & 31.0 & - & - & -- & 7.17 & 15,007 & 9,617 & 156.1 \\
\hline & 57.8 & 0.938 & 1.59 & -- & 8.45 & 16,705 & 10,336 & 154.3 \\
\hline & 67.0 & -- & - & -- & 9.50 & 17,785 & 10,737 & 157.4 \\
\hline \multirow{6}{*}{$\overline{3}$} & 37.0 & - & -- & -- & 4.08 & 12,835 & 6,721 & 159.9 \\
\hline & 41.0 & 0.403 & $0.61 \epsilon$ & 0.897 & 4.07 & 12,925 & 6,730 & 158.6 \\
\hline & 42.0 & -- & -- & - & 3.06 & 11,347 & 5,858 & 156.7 \\
\hline & 42.0 & -- & - & - & 3.06 & 11,347 & 5,858 & 136.7 \\
\hline & 50.0 & 0.978 & 1.63 & 2.33 & 9.64 & 17,398 & 10,890 & 159.9 \\
\hline & 52.0 & 0.789 & 1.29 & 1.93 & 9.91 & 17,901 & 10,890 & 160.5 \\
\hline \multirow[t]{2}{*}{4} & 50.5 & 1.70 & 2.27 & 3.65 & 10.18 & 18,737 & 11,048 & 156.7 \\
\hline & 79.0 & 1.23 & 1.66 & 3.10 & 9.72 & 18,021 & 10,850 & 157.4 \\
\hline
\end{tabular}

NOTES: $E_{d}=$ deformation modulus of elastlcity $\mathrm{E}_{\mathrm{D}}=$ dynamic modulus of elasticity $\nabla_{p}=$ compressional wave velocity

$v_{s}=$ shear wave velocity 


$$
\text { Ex }
$$




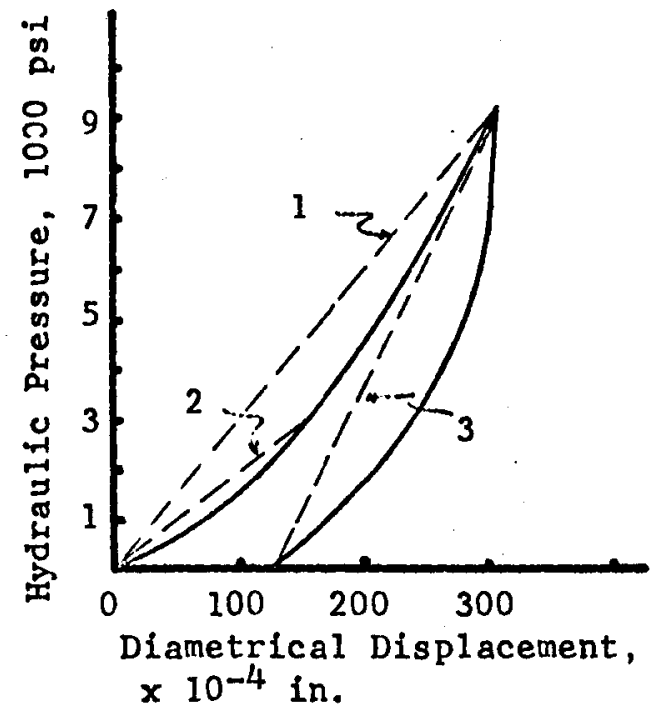

(a) Low-Angle Joint Zones

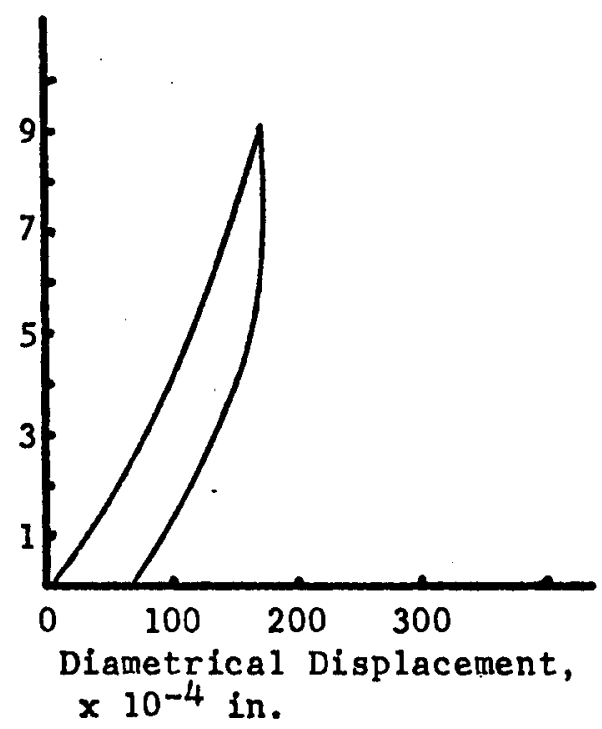

(b) High-Angle Joint Zones

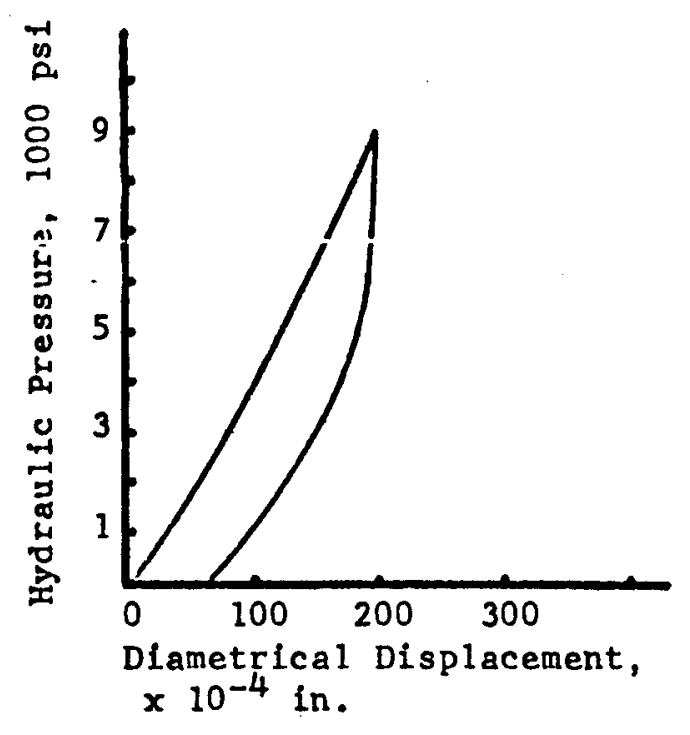

(c) Competent Rock Zones 

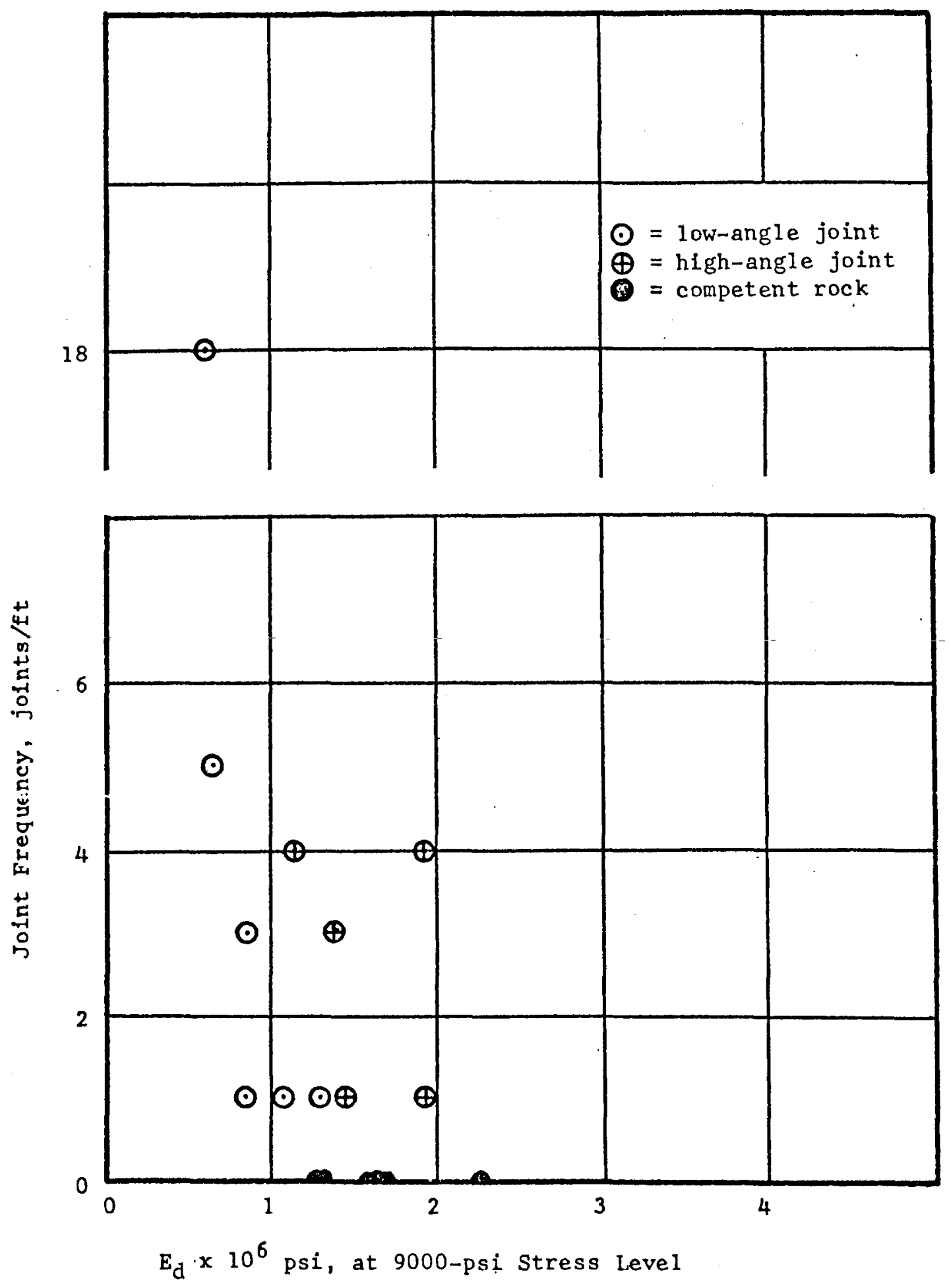

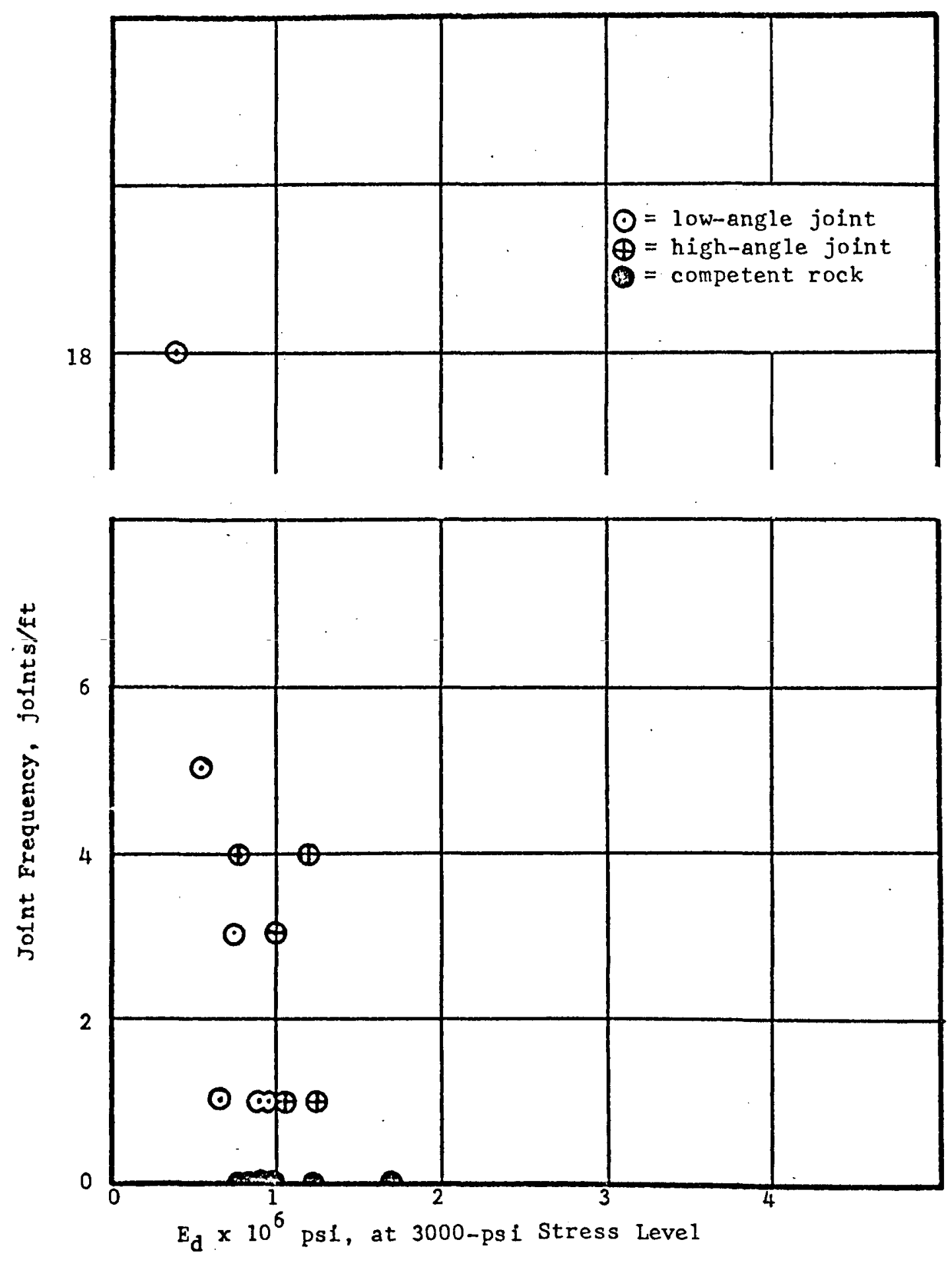

PLATE 4 

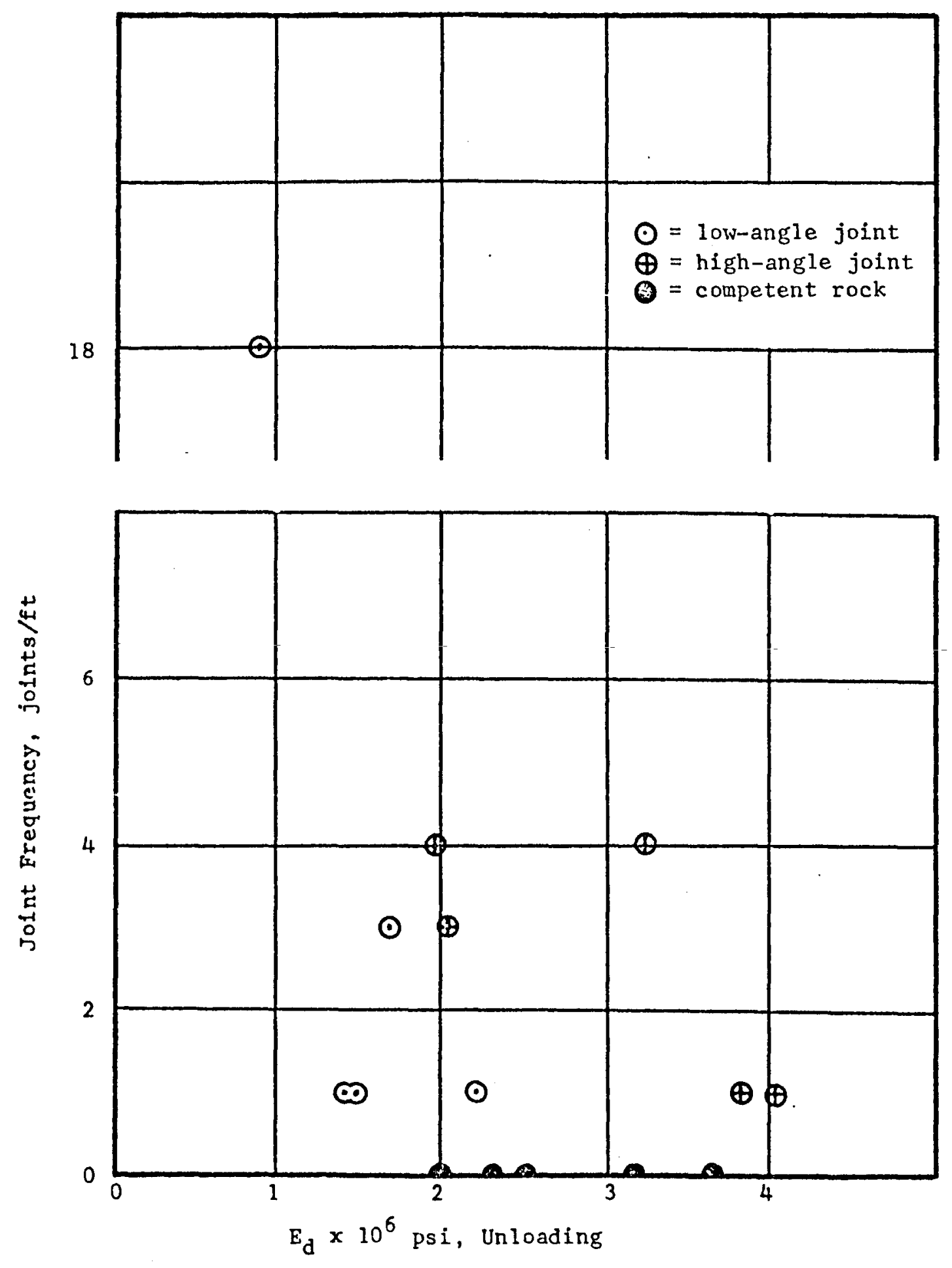

PLATE 5 


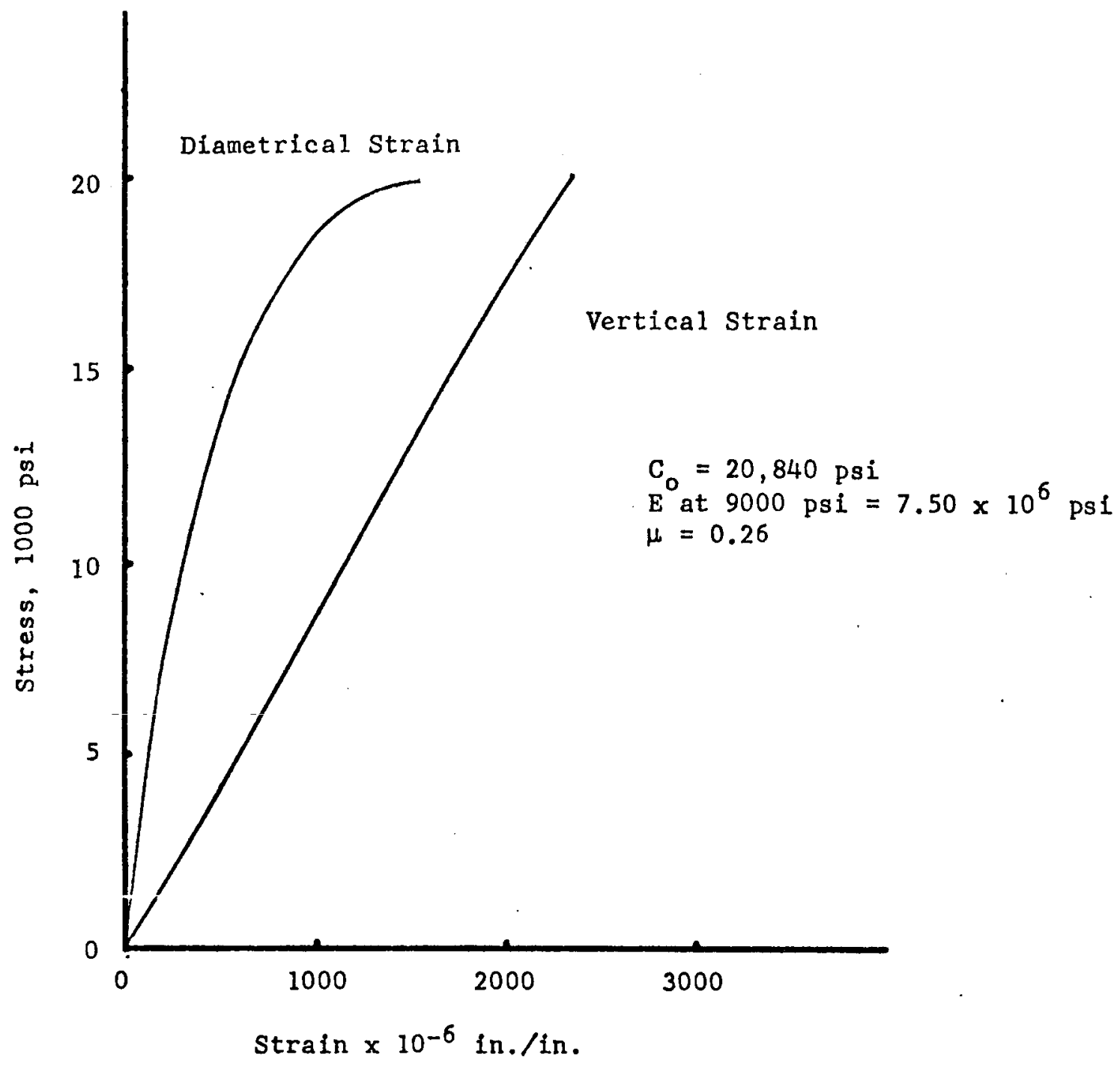



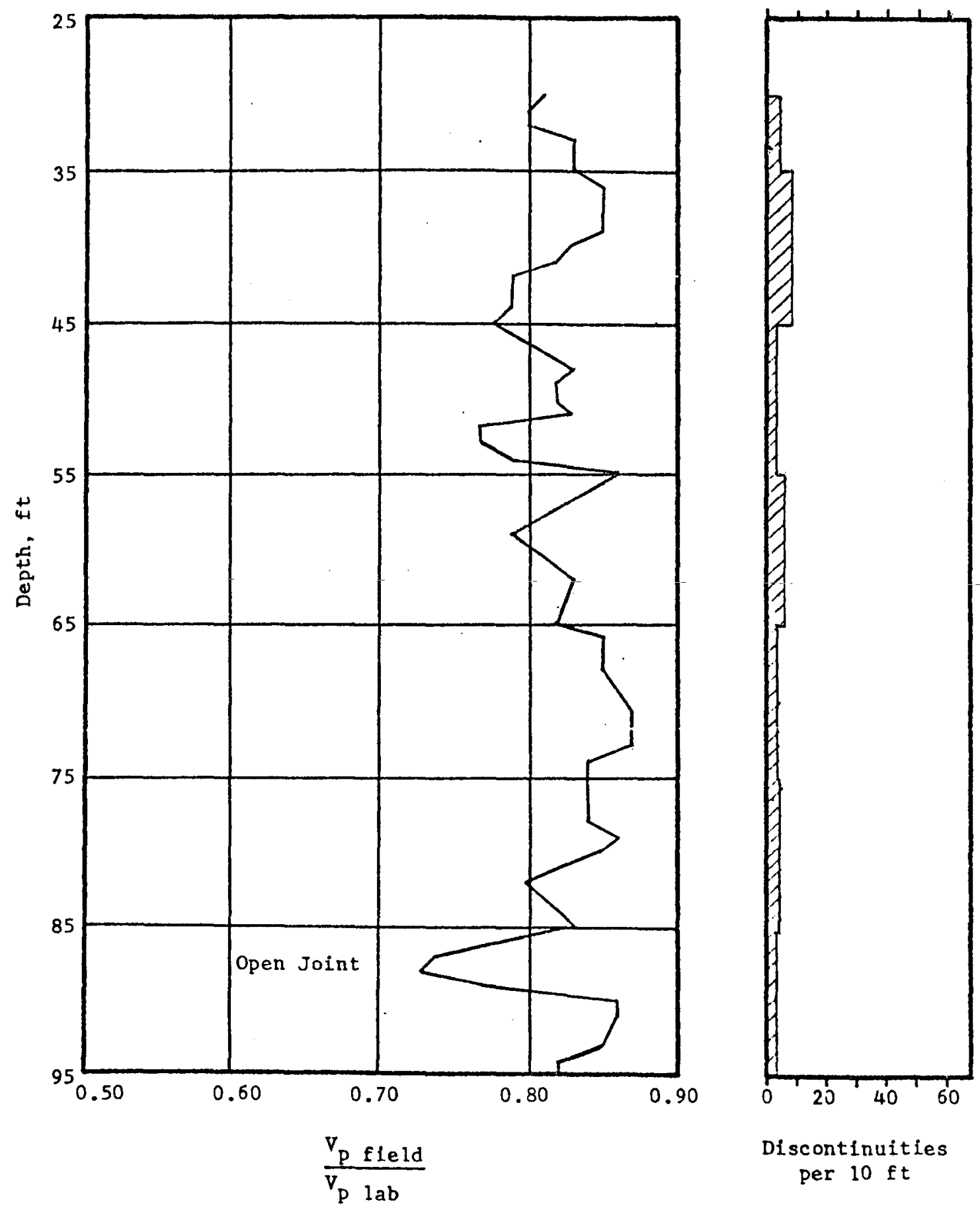

VELOCITY INDEX VERSUS DEPTH AND DISCONTINUITIES, HOLE 1

PLATE 7

69364 

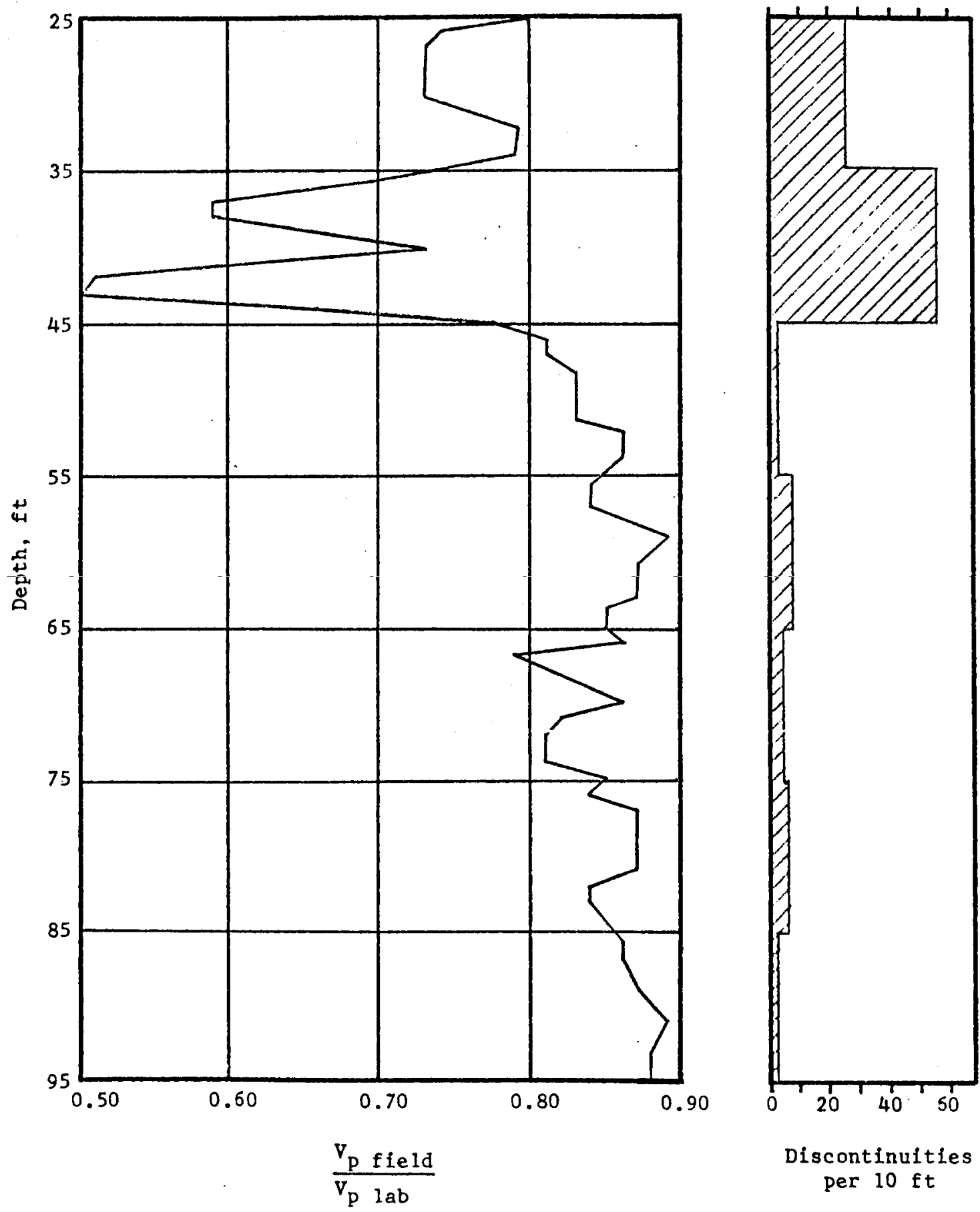

VELOCITY INDEX VERSUS DEPTH AND DISCONTINUITIES, HOLE 3 
Unclassified

Securty Clessification

\section{DOCUMENT CONTROL DATA - R \& D}

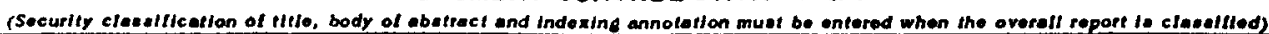

ORIGINA TING ACTIVITY (COrporate author)

U. S. Army Engineer Waterways Experiment Station, CE Vicksburg, Mississippi

3. REPONT TITLE

COMPARISON OF IN-SITU AND LABORATORY TEST RESULTS ON GRANTTE

4. DESCAIPTIVE NOTES (Type of roport and Incluaive dates)

Final report

8. AU THOR(S) (Flror namo, middlo Indlial, lool namo)

Richard L. Stowe

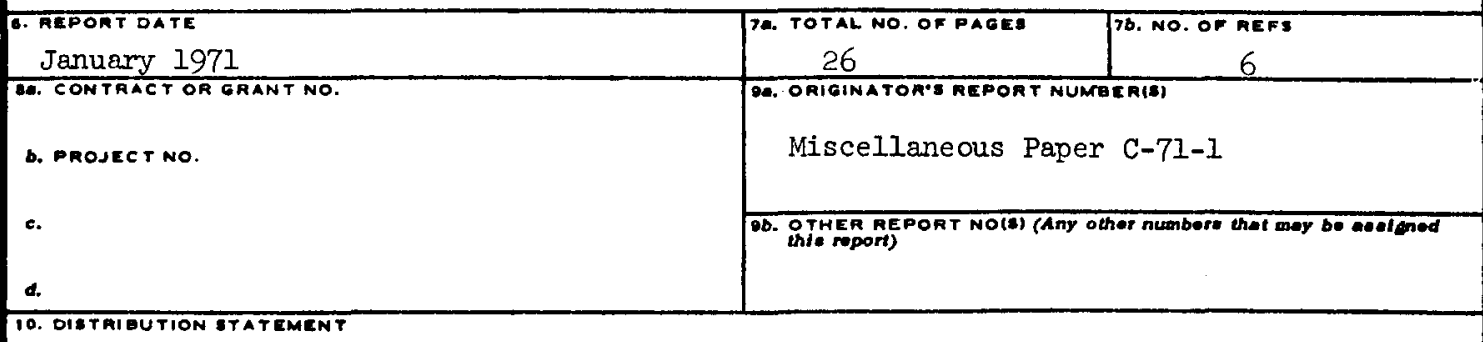

This document has been approved for public release and sale; its distribution is unlimited.

11. SUPPLEMENTARY NOTES

U. S. Air Force Systems Command, Space and Missile Systems Organization Norton Air Force Base, California

13. A6sthact Four NX-diameter holes were diamond-drilled in competent granite. Samples of the recovered core were used in laboratory tests. A borehole, plate-bearing device known as a Goodman jack was used to perform load-deformation tests on the rock in the core hole. The samples used in the laboratory tests were taken from depths in the hole at or within $5 \mathrm{ft}$ of those at which the jacking tests were made. Borehole camera records, compressional and shear wave velocities, and densities were measured. Dynamic elastic constants were computed for the in-situ material, while comparative data (except camera records) were obtained in the laboratory. These data were examined to evaluate the significance of the in-situ modulus of deformation $\left(E_{\alpha}\right)$, the value computed from Goodman-jack tests. Average test results show an excellent correlation between in-situ and laboratory data. The ratio of laboratory to field deformation modulus ranges from 9.82 to 7.21 for $3000-$ and $9000-p s i$ stress levels, respectively. The dynamic modulus ratio, $\frac{E_{D} \text { field }}{E_{D} \text { lab }}$, is 1.02 ; the compressional wave velocity ratio, $\frac{V_{p} \text { field }}{V_{p} l a b}$, is 0.94 ; the shear wave velocity ratio, $\frac{V_{s \text { field }}}{V_{s ~ l a b}}$, is 1.12 ; and the density ratio, $\frac{\gamma \text { field }}{\gamma \text { lab }}$, is 0.95 . 


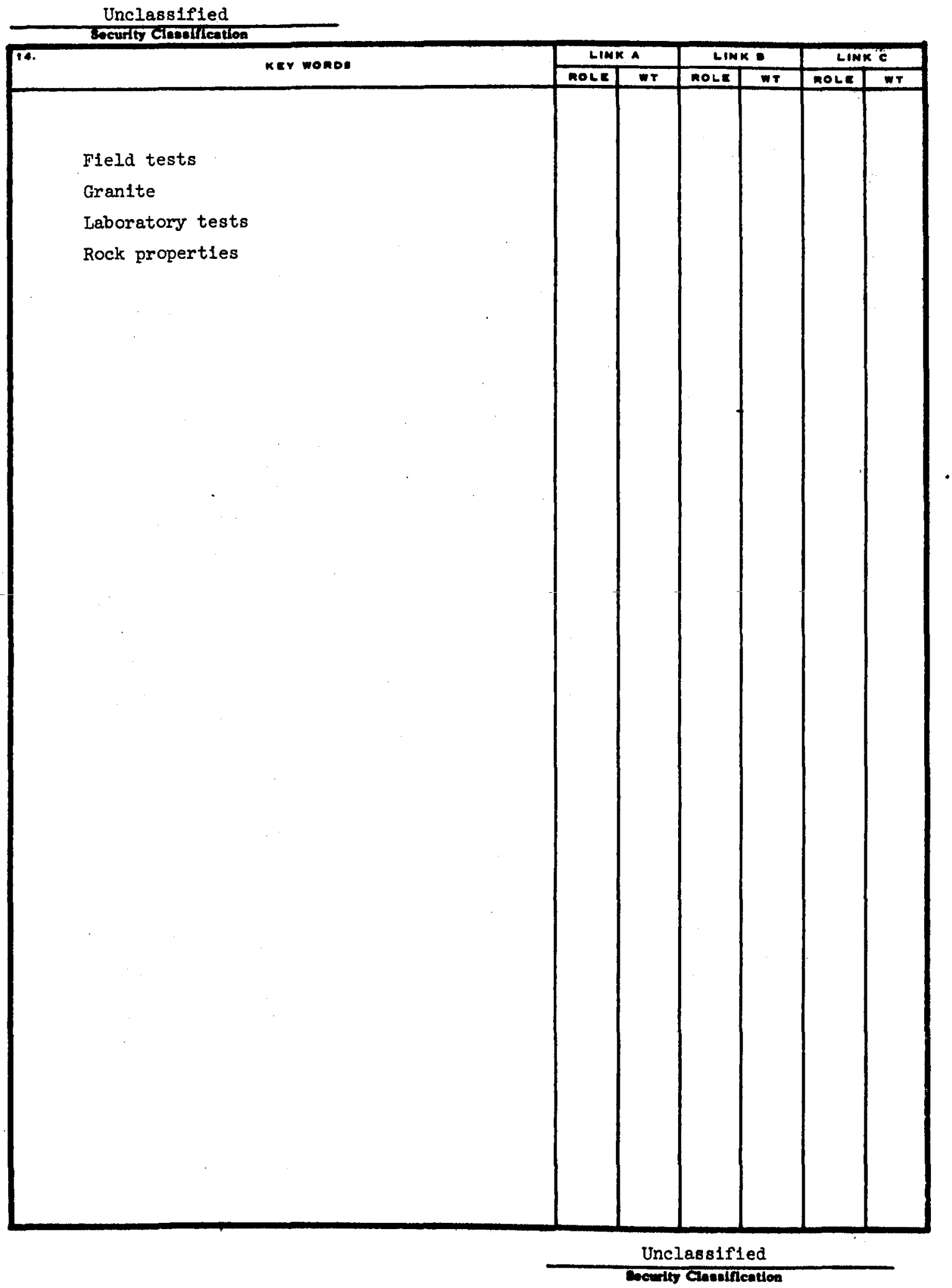

